\title{
Postoperative Benefit Evaluation Using Nasal Obstruction and Septoplasty Effectiveness (NOSE) Scale in Patients with a'Wengen Breathe Implant
}

Tatjana Bogdanova and Karina Jelagova

${ }^{1}$ Dr. Med. E. Jurshevich's clinic of aesthetic medicine, Riga, Latvia

${ }^{2}$ Riga Stradins Univercity, Medical department, 6th course, Riga, Latvia

\section{Introduction}

Shortness of breath due to nasal obstruction is common health problem. Nasal obstruction may occur due to inflammatory processes and a number of anatomic abnormalities of normal nasal structures such as septal deviation, enlargement of turbinates (concha bullosa), adenoid hypertrophy etc. One of causes of the obstruction is a collapse of internal nasal valve, which is a structure formed by the nasal septum, the caudal border of the upper lateral cartilage, the head of the inferior turbinate and the pyriform aperture and the tissues that surrounds it. Angle of the internal nasal valve area is the space between the nasal septum and the caudal part of upper lateral cartilage. For white patients the angle is normally $10-15^{\circ}$, as seen in Figure 1 .

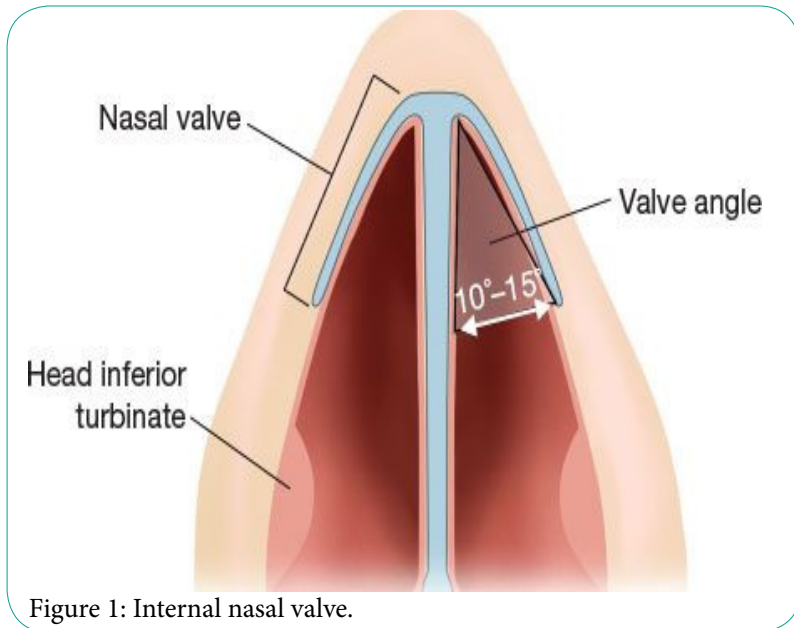

The narrowing of this angle can lead to significant breathing problems, as a result of this area being responsible for more than two thirds of the nose resistance capacity. Unfortunately, as seen in practice, in some cases this problem tends to be overlooked. Sometimes, patients undergo septoplasty and turbinoplasty without a positive effect on a shortness of breath problem, thus making it apparent that internal valve collapse was the cause of above-mentioned problem. In order to determine right diagnosis on a first patients visit, Cottle test, rhinoendoscopy, rhinomanometry and CT scan should be performed. If the breathing problems are due to internal nasal valve collapse, there are several methods that are used to resolve these occurred problems. The most simple and non-invasive method is the usage of nasal dilators, although, in some cases they are not effective enough. Invasive methods have some variations: sutures (to pull up the crus of lateral cartilage), grafts (spreader grafts, autospreader flaps, stairstep graft) and implants. This research studies patient with internal valve collapse that were subsequently fitted with an a'Wengen breathe implant. It expands the nasal vestibule by spreading the inner nasal valve and as a result solving obstruction problems. The implant is embedded in an open or closed surgical procedure by positioning it between the triangular cartilage and the alar cartilage and suturing it in place, as seen in Figure 2 and 3. Six sizes are available to ensure a

\section{Publication History:}

Received: August 03, 2016

Accepted: November 23, 2016

Published: November 25, 2016

\section{Keywords:}

Nasal obstruction, Nasal valve, a'Wengen Breath Implant
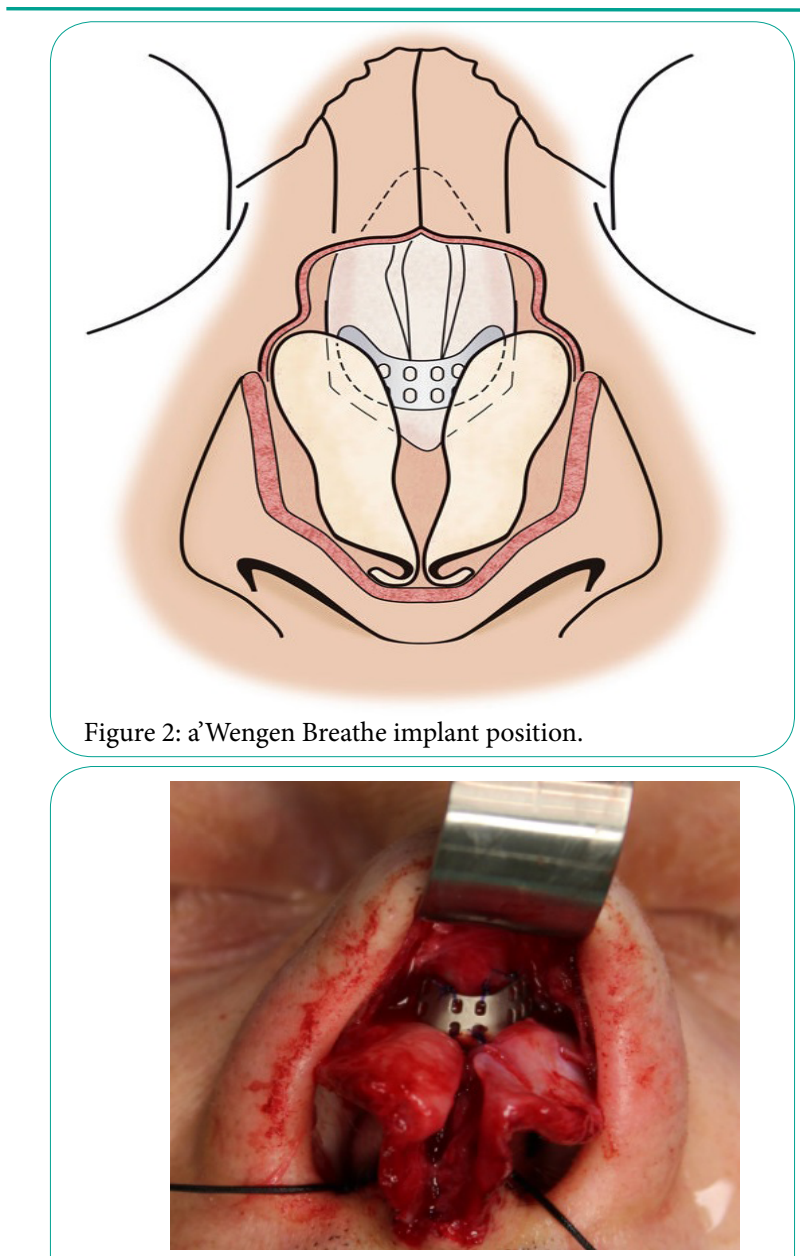

Figure 3: Wengen Breathe implant (intraoperative view)

"Corresponding Author: Dr. Tatjana Bogdanova, Dr. Med. E. Jurshevich's clinic of aesthetic medicine, Riga, Latvia; E-mail: orlbogdanova@inbox.Iv

Citation: Bogdanova T, Jelagova K (2016) Postoperative Benefit Evaluation Using Nasal Obstruction and Septoplasty Effectiveness (NOSE) Scale in Patients with a'Wengen Breathe Implant. Int J Surg Surgical Porced 1: 110. doi: http:// dx.doi.org/10.15344/ijssp/2016/110

Copyright: (c) 2016 Bogdanova et al. This is an open-access article distributed under the terms of the Creative Commons Attribution License, which permits unrestricted use, distribution, and reproduction in any medium, provided the original author and source are credited. 
Citation: Bogdanova T, Jelagova K (2016) Postoperative Benefit Evaluation Using Nasal Obstruction and Septoplasty Effectiveness (NOSE) Scale in Patients with a'Wengen Breathe Implant. Int J Surg Surgical Porced 1: 110. doi: http://dx.doi.org/10.15344/ijssp/2016/110

Page 2 of 3

proper and secure fit. In this study we use NOSE scale (translated to the Latvian and Russian lenguages) to evaluate symptom changes in preoperative and postoperative periods of implant insertion, despite the fact that it is originally used to evaluate septoplasty effectiveness.

\section{Aim}

To evaluate symptoms and life quality changes of patients undergoing a'Wengen implant operation in preoperative and postoperative periods using the NOSE scale and prove that it is appropriate tool for this mean.

\section{Methods}

In a case series descriptive study 17 patients ( 12 male and 5 female), aged between 22 and 59 years old, and were evaluated. During the time period from March, 2013 to April, 2016, patients were admitted to clinic over life quality decreasing due to breathing problems as a result of internal nasal valve collapse. All the patients had internal nasal valve angle narrowing with a positive Cottle test and a visible internal nasal valve narrowing on CT scan and endoscopicaly. Thus, based on the convicting Cottle test, CT scan and rhinoendoscopy results, all the patients have undergone a'Wengen Breathe implant insertion. Patients that have undergone other operations (septoplasty, turbinoplasty, rhinoplasty) were not included in the study to further increase the accuracy of the research results. Clinics' archives were used to record and preserve patients' data. NOSE scale was used for symptom evaluation. It contains 5 questions regarding well-being of the patients with five possible answers, as seen in Table 1. Each answer is estimated from 0 to 4 points, so the maximal possible point number for the test is 20 , the minimal 0 (lower score meaning better result). Initially, the NOSE scale is used to assess the effectiveness of septoplasty, but in the scope of this study the scale is adapted to evaluate symptoms and life quality changes of patients undergoing implant insertion. All the patients had to complete NOSE questionnaire before and after operation, as a part of study. Results of the questionnaire were analyzed using SPSS Statistics software (descriptive statistics; Wilcoxon signed-rank test).

As described by Lowry and Richard: "The Wilcoxon signed-rank test is a non-parametric statistical hypothesis test used when comparing two related samples, matched samples, or repeated measurements on a single sample to assess whether their population mean ranks differ" (2011).

\section{Methods}

17 patients aged from 22 to 59 years old were included, of whom 12 were male and 5 female. The average age was $\mathrm{M}=41.71$ years, $\mathrm{SD}= \pm$ 12.72 years. All the patients have undergone surgical a'Wengen Breathe implant insertion. Minimal time after operation was 1.5 months.
Maximum time - 34 months. Wilcoxon signed-rank test showed that 16 patients have experienced significant symptoms improvement according to relation between preoperative and postoperative NOSE results and 1 patient (Patient 17 in Table 3. and Table 4.) did not show any symptom changes (preoperative NOSE score and postoperative NOSE score were equal), $\mathrm{p}=0.001$ (Table 2). Before operation maximum score in NOSE questionnaire was 20 points, minimum 7 , $\mathrm{M}=14.94, \mathrm{SD}= \pm 3.071$ (Table 3); after operation maximum score - 18 points, minimum $0, \mathrm{M}=4.29, \mathrm{SD}= \pm 5.785$ (Table 4 ).

\begin{tabular}{|c|c|c|c|}
\hline \multicolumn{4}{|c|}{ Ranks } \\
\hline & $\mathrm{N}$ & Mean Rank & Sum of Rank \\
\hline $\begin{array}{c}\text { PostOP-PreOP } \\
\text { Negative Rank } \\
\text { Positive Rank } \\
\text { Ties } \\
\text { Total }\end{array}$ & $\begin{array}{l}16^{\mathrm{a}} \\
0^{\mathrm{b}} \\
1^{\mathrm{c}} \\
17\end{array}$ & $\begin{array}{l}8.50 \\
.00\end{array}$ & $\begin{array}{l}136.00 \\
.00\end{array}$ \\
\hline $\begin{array}{l}\text { a. } \text { PostOP }<\text { PreOP } \\
\text { b. PostOP }>\text { PreOP } \\
\text { c. PostOP }=\text { PreOP }\end{array}$ & & & \\
\hline
\end{tabular}

\begin{tabular}{|l|l|l|l|l|l|l|}
\hline \multicolumn{7}{|l|}{} \\
\hline $\begin{array}{l}\text { Patient/NOSE } \\
\text { question Nr. }\end{array}$ & Nr. 1 & Nr. 2 & Nr. 3 & $\begin{array}{l}\text { Nr. } \\
4\end{array}$ & Nr. 5 & Total \\
\hline Patient 1 & 3 & 1 & 2 & 3 & 4 & 13 \\
\hline Patient 2 & 3 & 3 & 2 & 3 & 2 & 13 \\
\hline Patient 3 & 2 & 0 & 2 & 2 & 1 & 7 \\
\hline Patient 4 & 4 & 3 & 4 & 3 & 4 & 18 \\
\hline Patient 5 & 3 & 2 & 3 & 1 & 3 & 12 \\
\hline Patient 6 & 4 & 3 & 4 & 3 & 3 & 17 \\
\hline Patient 7 & 3 & 3 & 3 & 3 & 3 & 15 \\
\hline Patient 8 & 3 & 4 & 2 & 2 & 3 & 14 \\
\hline Patient 9 & 4 & 4 & 3 & 4 & 4 & 19 \\
\hline Patient 10 & 4 & 4 & 4 & 4 & 4 & 20 \\
\hline Patient 11 & 3 & 0 & 4 & 4 & 4 & 15 \\
\hline Patient 12 & 3 & 3 & 3 & 2 & 3 & 14 \\
\hline Patient 13 & 3 & 2 & 3 & 4 & 4 & 16 \\
\hline Patient 14 & 3 & 2 & 3 & 3 & 4 & 15 \\
\hline Patient 15 & 4 & 3 & 2 & 2 & 13 \\
\hline Patient 16 & 3 & 3 & 2 & 3 & 15 \\
\hline Patient 17 & 3 & 4 & 2 & 4 & 18 \\
\hline
\end{tabular}

Table 3: Preoperative NOSE scale results (maximum score - 20, minimum -7).

\begin{tabular}{|l|l|l|l|l|l|}
\hline & Not a Problem & Mild Problem & Moderate Problem & Fairly Bad Problem & Severe Problem \\
\hline 1. Nasal congestion or stuffiness & 0 & 1 & 2 & 3 & 4 \\
\hline 2. Nasal blockage or obstruction & 0 & 1 & 2 & 3 & 4 \\
\hline 3. Trouble breathing through my nose & 0 & 1 & 2 & 3 & 4 \\
\hline 4. Trouble sleeping & 0 & 1 & 2 & 3 & 4 \\
\hline $\begin{array}{l}\text { 5. Unable to get enough air through my nose } \\
\text { during exercise or exertion }\end{array}$ & 0 & 1 & 2 & 3 & 4 \\
\hline
\end{tabular}

Table 1: Nasal Obstruction and Septoplasty Effectiveness (NOSE) Scale. 
Citation: Bogdanova T, Jelagova K (2016) Postoperative Benefit Evaluation Using Nasal Obstruction and Septoplasty Effectiveness (NOSE) Scale in Patients with a'Wengen Breathe Implant. Int J Surg Surgical Porced 1: 110. doi: http://dx.doi.org/10.15344/ijssp/2016/110

\begin{tabular}{|l|l|l|l|l|l|l|}
\hline $\begin{array}{l}\text { Patient/NOSE } \\
\text { question Nr. }\end{array}$ & Nr. 1 & Nr. 2 & Nr. 3 & Nr. 4 & Nr. 5 & Total \\
\hline Patient 1 & 0 & 0 & 0 & 1 & 1 & 2 \\
\hline Patient 2 & 1 & 0 & 0 & 0 & 0 & 1 \\
\hline Patient 3 & 0 & 0 & 0 & 0 & 0 & 0 \\
\hline Patient 4 & 2 & 1 & 2 & 2 & 3 & 10 \\
\hline Patient 5 & 0 & 0 & 0 & 0 & 0 & 0 \\
\hline Patient 6 & 0 & 0 & 0 & 0 & 0 & 0 \\
\hline Patient 7 & 2 & 1 & 1 & 2 & 2 & 8 \\
\hline Patient 8 & 1 & 1 & 0 & 0 & 0 & 2 \\
\hline Patient 9 & 1 & 0 & 0 & 0 & 0 & 1 \\
\hline Patient 10 & 0 & 0 & 0 & 0 & 0 & 0 \\
\hline Patient 11 & 2 & 0 & 3 & 4 & 4 & 13 \\
\hline Patient 12 & 0 & 0 & 0 & 0 & 0 & 0 \\
\hline Patient 13 & 2 & 2 & 3 & 3 & 3 & 13 \\
\hline Patient 14 & 0 & 0 & 0 & 0 & 0 & 0 \\
\hline Patient 15 & 1 & 0 & 1 & 0 & 0 & 2 \\
\hline Patient 16 & 2 & 1 & 0 & 0 & 0 & 3 \\
\hline Patient 17 & 4 & 4 & 4 & 2 & 4 & 18 \\
\hline
\end{tabular}

Table 4: Postoperative NOSE scale results (maximum score - 18, minimum - 0).

\section{Conclusion}

NOSE scale results showed significant differences before and after operation. Improvement of symptoms after a'Wengen Breathe implant operation were detected in 16 patients' cases, 1 case had no changes. Consequently, according to the prevalence of patients with positive dynamics, it can be concluded that NOSE scale is a proper tool for evaluation of symptom and life quality changes in patients with a'Wengen Breathe implant.

This study is going to be continued performing preoperative and postoperative rhinomanometry to further patients undergoing a'Wengen Breathe implant insertion.

\section{Competing Interests}

The authors declare that they have no competing interests.

\section{References}

1. http://emedicine.medscape.com/article/877468-overview

2. https://www.karlstorz.com/cps/rde/xbcr/karlstorz_assets ASSETS/3060800.pdf

3. https://www.entnet.org/sites/default/files/NOSE-Instrument.pdf

4. Concepts \& Applications of Inferential Statistics.

5. http://www.schweizer-illustrierte.ch/lifestyle/gesundheit-und-fitness/starkeschnarcher-leben-gefaehrlich.

6. http://www.breathe-implant.com/

7. anatomy 